

\title{
O GOVERNO DILMA FRENTE AO "TRIPÉ MACROECONÔMICO" E À DIREITA LIBERAL E DEPENDENTE
}

\author{
Luiz CARLOS BRESSER-PEREIRA
}

Quando a presidente Dilma Rousseff foi eleita, no final de 2010, com o apoio decisivo do presidente Lula, a sociedade brasileira supôs e a nova presidente confirmou que seu governo seria uma continuação do anterior. Entretanto, como esse governo não foi capaz de romper com a política do "tripé macroeconômico" dominante no Brasil desde 1999, o governo Dilma só seria bem-sucedido se rompesse a armadilha de juros altos e câmbio sobreapreciado que caracteriza essa política ortodoxa. Algo que, depois de dois anos de governo, vemos que ela tentou fazer, mas foi apenas parcialmente bem-sucedida. O que provavelmente explica por que, por enquanto, os resultados de seu governo foram medíocres em termos de crescimento do PIB: 2,7\% em 2011 e cerca de 1\% em 2012. Mas será realmente macroeconômica a causa desses resultados, como estou sugerindo? Por que, não obstante, a presidente apresenta recordes de aprovação popular que superam mesmo os de Lula? E por queessa popularidade tem base nos pobres, já que os ricos (a classe alta e a classe média superior) e a mídia que controlam revelam tanta hostilidade em relação à presidente?

\section{GOVERNO LULA}

O governo Lula foi um governo bem-sucedido, como demonstraram os altos índices de popularidade alcançados e a neutralização das críticas da direita conservadora. Foi só um ano depois de terminado, em 2012, que o liberalismo conservador e moralista brasileiro se reorganizou para criticá-lo. O governo Lula teve êxito porque logrou quase dobrar a taxa de crescimento, porque diminuiu a desigualdade e melhorou o padrão de vida de milhões de brasileiros, e porque alcançou grande prestígio internacional. Mas esse sucesso não se deveu à política macroeconômica que adotou, e sim, respectivamente, à sorte de os preços das commodities exportadas pelo Brasil terem crescido extraordinariamente durante seu governo, à política de salário mínimo e de transferências de renda, e a uma política internacional independente e criativa. 
Mas em relação à política macroeconômica seu governo não foi bem-sucedido. Ele não logrou escapar da armadilha que é o "tripé macroeconômico" herdado dos governos anteriores, e, portanto, não logrou baixar substancialmente a taxa de juros, e, principalmente, não logrou neutralizar a tendência à sobreapreciação cíclica e crônica da taxa de câmbio que existe no Brasil. Assim, em 31 de dezembro de 2010 , quando terminou seu governo, a taxa de juros real continuava elevada em comparação aos demais países, e a taxa de câmbio estava absurdamente sobrevalorizada, a R \$ 1,65 por dólar - o que inviabilizava o desenvolvimento do país.

O crescimento que se registrou a partir de 2006 foi, portanto, passageiro, foi devido à conjuntura internacional favorável e ao aumento do mercado interno proporcionado pela elevação dos salários reais e pela ampliação do crédito ao consumidor. Graças ao aumento do rendimento das camadas pobres, acentuado pela valorização do real (no curto prazo a desvalorização cambial aumenta os salários), vimos a transferência de uma grande parte da população brasileira da classe $\mathrm{D}$ para a $\mathrm{C}$, formando-se assim no Brasil um consumo de massas novo. Dessa forma, a indústria, que se viu impedida de exportar devido à valorização cambial, foi temporariamente compensada pelo aumento do mercado interno. Temporariamente porque, com a taxa de câmbio a $\mathrm{R} \$ 1,65$ ou mesmo de $\mathrm{R} \$ 2$, 00 por dólar, a maioria das empresas industriais brasileiras competentes tecnologicamente não tem condições de exportar nem de enfrentar a concorrência no mercado nacional das importações.

Afinal, o governo Lula deixou que sua política macroeconômica fosse dominada pelo objetivo do controle da inflação, e, para isso, recorreu a um mecanismo clássico e perverso: a apreciação cambial. Houve apenas dois grandes momentos em que o governo manifestou independência - foi quando o ministro Guido Mantega estabeleceu um imposto sobre as entradas de capital, rompendo com a ortodoxia que condenava qualquer controle de capital, e quando, diante da crise financeira global de 2008 , realizou uma política contracíclica competente baixando impostos e ampliando substancialmente o crédito dos bancos públicos. Mas, afinal, o governo se deixou vencer pela tendência à sobreapreciação da taxa de câmbio que existe nas economias em desenvolvimento.

\section{HERANÇA MACROECONÔMICA}

Em consequência, a herança macroeconômica que a presidente Dilma recebeu foi pesada: uma taxa de juros elevada, e uma taxa de câmbio altamente sobreapreciada. E no início de seu governo, em janeiro de 2011 , o país já não podia mais contar com aumento dos preços 
[1] Cuja criação, aliás, foi um grande erro: pretendendo continuar Estados-nação soberanos, os países que o criaram haviam substituído sua moeda nacional (essencial para essa soberania) pelo euro, uma "moeda estrangeira" - estrangeira porque os países que a adotaram não podem nem emiti-la, nem desvalorizá-la. das commodities exportadas que haviam tanto beneficiado seu antecessor. Entretanto, isso não estava claro para a maioria dos analistas. Como nos oito anos do governo Lula a taxa de crescimento anual do PIB passara de 2,5\% para cerca de 4,5\%, e como seu principal determinante, a taxa de investimento, aumentou de $17 \%$ para $19 \%$, esses analistas concluíram de forma otimista que o Brasil havia, afinal, retomado o desenvolvimento econômico paralisado muito tempo atrás, em 1980. Essa conclusão era apressada e sem fundamento teórico. Era apressada porque o crescimento econômico durante os dois primeiros anos do governo logo a desmentiram. Não tinha fundamento teórico porque os otimistas não se deram conta de que o crescimento no governo Lula derivara de condições externas favoráveis, não tendo sido capaz de superar o obstáculo fundamental ao desenvolvimento brasileiro: a armadilha da alta taxa de juros em relação aos padrões internacionais e da taxa de câmbio sobreapreciada.

Além disso, a situação internacional, que melhorara depois da crise financeira global de 2008 , voltou a se deteriorar em 2011 devido à recuperação insatisfatória da economia americana e, principalmente, à grave crise do euro ${ }^{1}$. Em consequência, todos os países ricos apresentaram taxas de crescimento muito baixas senão negativas em 2012, ea demanda pelos bens exportados pelo Brasil diminuiu.

\section{GRÁFICO}

Produção física da indústria geral e volume de vendas do comércio varejista (ambas com ajuste sazonal)

Índice: jan. $/ 2000=100$

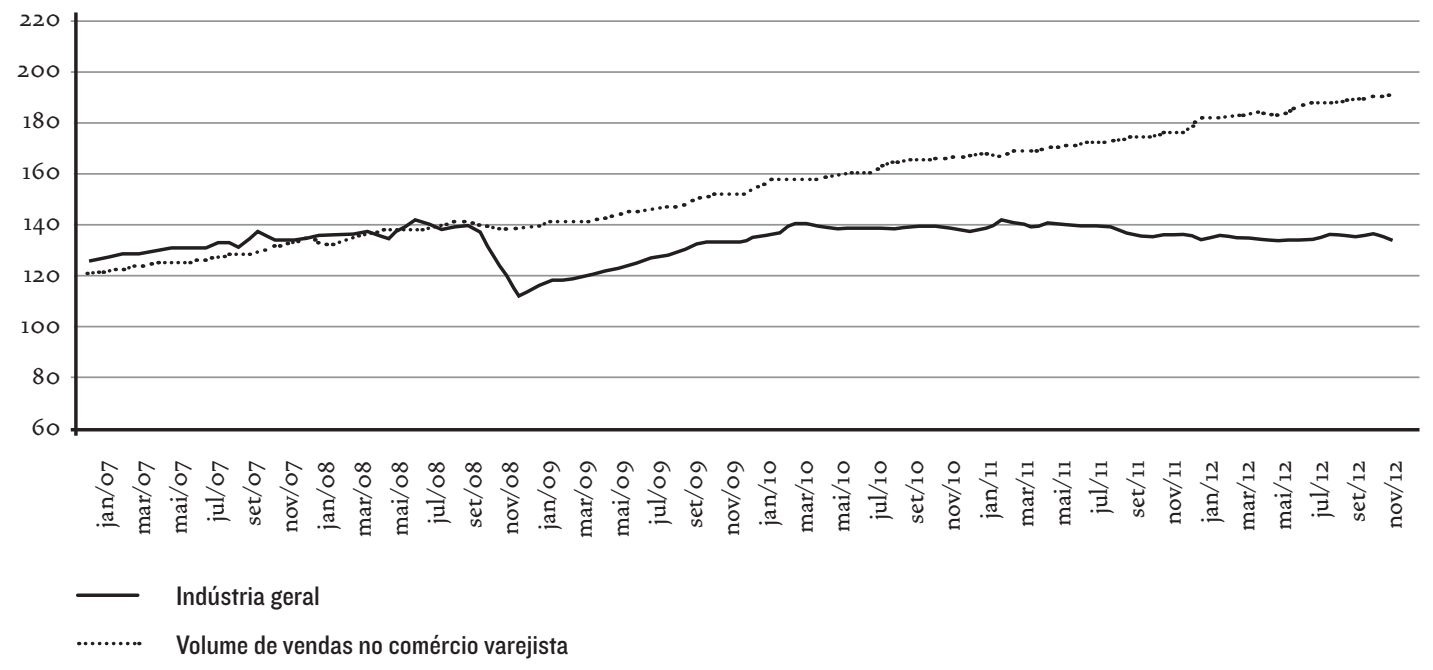


Mas a política econômica de Lula não foi desenvolvimentista? Não é ser desenvolvimentista voltar-se para o mercado interno? E não foi isso o que fez seu governo? O objetivo de qualquer bom governo é aumentar o mercado interno, mas em uma economia razoavelmente aberta como é a brasileira não se logra esse objetivo estimulando-se o consumo de massa enquanto a taxa de câmbio se aprecia. Quando se faz isso, o mercado interno é tomado pelos importadores depois de aproximadamente três anos (o tempo que demora para que importadores de bens industriais se organizem para importar), e a indústria nacional perde acesso tanto ao mercado externo quanto ao interno. Foi precisamente o que aconteceu no Brasil. O gráfico com a produção física da indústria e as vendas do varejo mostra com clareza esse fenômeno. Enquanto as vendas aos consumidores continuam a aumentar normalmente, a produção industrial sofre uma queda em 2009 , e depois continua a se distanciar das vendas do comércio.

Em outras palavras, o governo Lula não logrou enfrentar os problemas de baixo crescimento e de desindustrialização que ocorrem desde que uma grande crise financeira (a crise da dívida externa dos anos 1980) interrompeu o crescimento do Brasil:entre 1930 e 1980 o Brasil cresceu a uma taxa média de $4 \%$, a partir de 1981 até 2012 , apenas $1 \%$ ao ano. Nos anos 1980 a quase estagnação deveu-se à própria crise financeira e à alta inflação. Depois da abertura comercial e financeira de 1990-92 e da estabilização de preços de 1994, deveu-se à armadilha econômica representada pelo tripé, ou, em outras palavras, pela política ortodoxa do chamado "Novo Consenso Econômico" - que se tornou dominante nos Estados Unidos nos anos 1990 e levou à crise financeira global de 2008 - e que foi aplicada no Brasil por economistas com o devido ph.D. obtido no Norte ${ }^{2}$.

Assim, em vez de o país buscar a estabilidade financeira garantida por uma taxa de câmbio competitiva, decidiu consumir no curto prazo e apresentar déficits crônicos em conta corrente; e em vez de visar o aumento da produtividade pela industrialização, ou, mais genericamente, pela transferência de mão de obra de setores com baixo valor adicionado per capita para setores com alto valor adicionado per capita, que são tecnologicamente mais sofisticados e pagam maiores salários, o Brasil, desde 1994, aceita reduzir o aumento da produtividade da economia através da transferência inversa e a transformação da economia brasileira na "fazenda do mundo".

Por outro lado, como o setor primário (agricultura, pecuária e mineração) não tem capacidade de absorvero desemprego industrial (ou a falta do aumento de postos ofertados), quem absorve a mão de obra é o setor de serviços, inclusive o setor comercial que é alimentado pelas importações. E temos assim a situação aparentemente paradoxal de baixo crescimento e pleno emprego. Na verdade, não há nada de
[2] O Novo Consenso Econômico é um conjunto de políticas macroeconômicas que se tornou dominante nos meios universitários ortodoxos ou neoclássicos nos anos 1990, depois que o monetarismo se revelou incapaz de orientar a ação dos bancos centrais. Para esse "consenso", a política de metas de inflação é central, e o único instrumento legítimo disponível é a política de juros. O pressuposto é de que bastaria isso e o equilíbrio fiscal para que as economias que o utilizassem tivessem garantido crescimento e estabilidade. 
[3] Devo essa frase tão sardônica quanto significativa a Gabriel Palma.

[4] Cf. O Estado de S. Paulo, 21 de abril de 2012. paradoxal nisso. Há simplesmente uma política econômica ortodoxa absurda para a qual não há diferença para o país entre produzir "potato chips" e "digital chips"3.

\section{A NOVA POLÍTICA MACROECONÔMICA}

A presidente Dilma Rousseff começou seu governo com uma proposta de continuidade do governo Lula; mais do que isso, com a esperança de poder reeditar o desempenho de seu antecessor, que combinara taxas relativamente elevadas de crescimento com redução da desigualdade econômica. Mas recebeu para governar um país cuja economia continuava a crescer a uma taxa muito inferior àquela que é necessária para um verdadeiro catching up, porque seu antecessor não havia enfrentado o desequilíbrio macroeconômico fundamental ao adotar um "tripé macroeconômico" insistentemente celebrado pelos economistas ortodoxos.

O tripé macroeconômico ortodoxo (superávit primário, câmbio flutuante e meta de inflação) é constituído por esses três conceitos genéricos que, afinal, resultam em dois parâmetros e um único objetivo que interessam a uma coalizão política neoliberal formada por capitalistas rentistas e financistas. Os dois parâmetros são uma taxa de juros nominal a mais alta possível e uma taxa de inflação a mais baixa possível; o objetivo finaléuma taxa de juros real elevada, que remunere os capitalistas rentistas e os financistas que administram sua riqueza. Há pouca dúvida de que o país deve apresentar um superávit primário, ou, mais precisamente, ser responsável do ponto de vista fiscal. Já é inaceitável que um país em desenvolvimento renuncie a uma política de taxa de câmbio e a deixe flutuar livremente no mercado quando sabemos que nos países em desenvolvimento existe uma tendência à sobreapreciação cíclica e crônica da taxa de câmbio. E é igualmente inaceitável que a política de metas de inflação subordine os dois outros objetivos que devem ter uma boa política macroeconômica: uma taxa de câmbio competitiva e um razoável pleno emprego. É ótimo que haja uma meta de inflação, desde que os responsáveis pela política econômica tenham também uma meta de câmbio e uma meta de crescimento, e façam os difíceis compromissos entre essas três metas.

Dilma Rousseff compreendeu desde o início a necessidade de rever a política do tripé. Ela é uma economista desenvolvimentista, e, em discurso de 20 de abril de 2012 , por ocasião da formatura de novos diplomatas, declarou que para se desenvolver o Brasil precisa "equacionar as três amarras do país: taxa de juros alta, câmbio e impostos altos"4. Quando Alexandre Tombini assumiu a presidência do Banco Central, o banco voltou a se identificar com os interesses nacionais, e deixou de haver um conflito permanente com o Mi- 
nistério da Fazenda, que se tornara desenvolvimentista desde que Guido Mantega passou a dirigi-lo em 2006. Assim apoiada, a presidente logrou reduzir substancialmente a taxa de juros em termos nominais e reais, e esta afinal caiu para cerca de $3 \%$ ao ano, e a taxa de câmbio se depreciou de $\mathrm{R} \$ 1,65$ para cerca de $\mathrm{R} \$ 2,05$ por dólar. Mas essas mudanças, especialmente a relativa à taxa de câmbio, estão longe de serem suficientes. A taxa de câmbio competitiva ou "de equilíbrio industrial" no Brasil (a taxa de câmbio que torna competitivas empresas utilizando tecnologia no estado da arte mundial)é de cerca de $\mathrm{R} \$ 2,75$ por dólar, conforme demonstrou Nelson Marconi5. De forma que a indústria brasileira não saiu de sua condição de crise permanente e de desindustrialização.

Por quê? Essencialmente porque não tem o apoio na sociedade civil brasileira necessário para realizar essa mudança - no qual o peso de uma direita liberal e dependente é muito grande. O que se conseguiu, depois de dez anos de crítica ${ }^{6}$, foi o apoio da sociedade para a redução das absurdas taxas de juros defendidas pela ortodoxia econômica. Já em relação à taxa de câmbio, o que se logrou foi colocar o problema na agenda nacional. Mas não foi possível persuadir a sociedade quanto à necessidade e possibilidade de se adotar uma política de taxa de câmbio que faça com que o real flutue não mais em torno do equilíbrio corrente mas do equilíbrio industrial, porque os cidadãos têm dificuldade em compreender o papel da taxa de câmbio no desenvolvimento econômico, e porque a hegemonia da ortodoxia liberal é ainda muito grande, apesar da desmoralização causada pela crise financeira global de 2008. A ortodoxia naturalmente rejeita o diagnóstico novo-desenvolvimentista para o baixo crescimento do país, que o explica pela alta taxa de juros e a taxa de câmbio sobreapreciada. Em seu lugar continua afirmando que o problema do Brasil seria a baixa poupança, e, naturalmente, a falta das reformas institucionais liberalizantes "mágicas" que permitiriam tornar os mercados mais livres e todo o sistema econômico mais eficiente. Não perderei tempo em relação a esta segunda tolice. Quanto ao nível de poupança, no Brasil, de fato, eleé baixo, mas, de acordo com a lógica keynesiana, para que ele aumente é preciso que antes aumente o investimento ${ }^{7}$, o que depende de duas providências: primeiro, que a taxa de juros seja moderada e a taxa de câmbio seja tornada competitiva, localizada no nível do equilíbrio industrial, porque as empresas só investem quando há oportunidades de investimentos lucrativos para os empresários algo que se reduz à medida que se aprecia a taxa de câmbio e sobem os juros; segundo, que o Estado realize uma poupança pública positiva, em vez de apenas alcançar um superávit primário. Ora, não obstante o avanço realizado nos primeiros dois anos do governo Dilma, a taxa de juros real ainda continua alta quando comparada com a dos demais
[5] Marconi, Nelson. "The industrial equilibrium exchange rate in Brazil: an estimation". Brazilian Journal of Political Economy, 32 (4), 2012, pp. 656-69.

[6] Elas começaram de forma sistemática em 2002 com dois trabalhos: Bresser-Pereira, L. C. e Nakano, Y. "Uma estratégia de desenvolvimento com estabilidade". Revista de Economia Política, 21(3), 2002, pp. 146-77; e Bresser-Pereira, L. C. "Financiamento para o subdesenvolvimento: o Brasil e o Segundo Consenso de Washington". In: Castro, Ana Célia (org.).Desenvolvimento em debate:painéis do desenvolvimento brasileiro. Rio de Janeiro: Mauad/BNDES, 2002, vol. 2, pp.359-98.

[7] Desde que o empresário conte com financiamento, é o investimento que determina a poupança, e não o inverso como pretende a teoria econômica neoclássica, mais especificamente a "teoria do porquinho", segundo a qual é necessário, primeiro, poupar, e, depois de bem enchido o cofre, investir. 
[8] "Endividamento do Estado e setor financeiro no Brasil: interdependências macroeconômicas e limites estruturais ao desenvolvimento". In: Almeida Magalhães, J. P. e outros. Os anos Lula: contribuições para um balanço crítico. Rio de Janeiro: Garamond, 2012, p. 83 . países. E a taxa de câmbio continua substancialmente sobreapreciada, muito distante do equilíbrio industrial de $\mathrm{R} \$ 2,75$.

Mais especificamente, o governo tem dificuldade em promover a desvalorização necessária da taxa de câmbio porque ela conflita com interesses. Em primeiro lugar, porque o poder dos exportadores de commodities tem impedido que se imponha um imposto variável sobre suas exportações que permita que a taxa de câmbio se aproxime do nível de equilíbrio industrial. Segundo, porque o governo teme o pequeno aumento da inflação que decorrerá da depreciação. Terceiro, porque teme as consequência impopulares da redução dos salários que ocorrerá no curto prazo, não obstante ela seja temporária (um pouco adiante, com o aumento dos investimentos e do crescimento, os salários passarão a aumentar fortemente). E, finalmente, porque bancos e empresas endividadas em moeda forte não querem ouvir falar de desvalorização cambial.

Quanto à poupança pública para financiar os investimentos públicos - esta continua uma questão fora da agenda do país, que aceita e cumpre desde 1999 a meta de superávit primário igual aos juros reais sobre a dívida pública menos a taxa de crescimento do PIB. Essa meta permite manter a relação dívida pública/PIB constante, e permite que a dívida pública continue a ser um elemento fundamental de liquidez para o sistema financeiro nacional. Mais amplamente, e em conjunto com a política de aumento de reservas que o governo vem realizando através do aumento da dívida pública interna, permite que a dívida pública tenha se tornado, conforme enfatizou Miguel Bruno, "o principal eixo da acumulação rentista-patrimonial do período 1991-2008"8. É por meio dela que se garante liquidez ao sistema financeiro brasileiro, e se viabiliza a financeirização - a multiplicação dos ganhos financeiros através do uso de "inovações" financeiras - principalmente de derivativos. Entretanto, essa meta fiscal não viabiliza o financiamento dos investimentos públicos pela poupança pública, como seria ideal em um quadro em que, neutralizada a doença holandesa e controladas as entradas excessivas de capital, ao invés de apresentar déficit, o país apresentaria um superávit em conta corrente. A meta necessária para que os investimentos públicos voltem a ter importância na formação bruta do capital do país é al cançar um resultado fiscal que seja igual à diferença entre a receita pública e a despesa de consumo, mais os recursos necessários para financiar os investimentos públicos, e menos a taxa de crescimento do PIB. Dessa forma a dívida pública permaneceria sob controle e os investimentos públicos poderão representar entre $20 \%$ e $25 \%$ do investimento total - um valor compatível com a necessidade de investimentos do setor não competitivo da economia onde a presença do Estado deve ser dominante. 
Enquanto não resolver o desequilíbrio macroeconômico representado por uma poupança pública insuficiente e pela sobreapreciação cíclica e crônica da taxa de câmbio, além de não atingir as taxas de crescimento necessárias para o catching up, o país continuará a se desindustrializar prematuramente. Em outras palavras, enquanto não criar boas oportunidades de investimentos para os empresários, seja mantendo a taxa de câmbio no equilíbrio industrial para tornar competitivas internacionalmente as empresas que utilizam tecnologia no estado da arte mundial, seja realizando investimentos que criam demanda para o setor privado, o país não estará resolvendo o problema do seu desenvolvimento pelo lado da demanda. Em consequência, todos os esforços que o país vem realizando no lado da oferta, no sentido de desenvolver a educação, a ciência, a tecnologia e investir na infraestrutura, serão desperdiçados.

Tanto para colocar a taxa de câmbio no nível correto quanto para aumentar a taxa de investimento público, a presidente enfrenta, portanto, problemas econômicos que são, em última análise, políticos, porque nenhum presidente logra governar sem um razoável apoio na sociedade. E esse desafio é sempre maior para um presidente de esquerda, dada a violenta oposição de direita. Esta, seguindo uma velha e conhecida lógica, tentou, durante 2011, cooptar a nova presidente. Quando verificou que isso era impossível - que a presidente estava disposta a fazer compromissos mas não se dispunha a abandonar seus princípios - ela passou para o ataque. Aproveitando o processo do mensalão, atacou mais violentamente o ex-presidente Lula e o PT, mas afinal esse era um ataque a ela. E quando o PIB de 2012 se revelou decepcionante, atacou a competente política industrial da presidente, afirmando que eram tantas as medidas adotadas que os empresários brasileiros ficavam "confusos". Ora, isso não é teoria econômica, é "voodoo economics", teoria econômica primitiva de quem não tem argumentos sérios a apresentar. É verdade que essas medidas não compensam o juro alto e principalmente a sobreapreciação do real, mas não há dúvida de que elas são positivas.

\section{CONCLUSÃO}

A presidente Dilma Rousseff enfrenta, portanto, grandes dificuldades para mudar a equação macroeconômica brasileira. Mas ela tem personalidade e caráter fortes, demonstra sempre um grande espírito público, conhece bem os problemas macroeconômicos que o país enfrenta, e sabe fazer os compromissos políticos necessários. Talvez essas qualidades somadas afinal lhe permitam retomar o desenvolvimento brasileiro. São qualidades diferentes das de seu antecessor.Ambos são políticos de esquerda moderada, social-desenvolvimentista, 
[9] Vianna, Luiz Werneck. "O Cachoeira e a gota d'água". O Estado de S. Paulo, 22 de abril de 2012 . ambos são nacionalistas e comprometidos com a construção de um capitalismo social menos injusto, mas Lula é antes um político carismático voltado para os trabalhadores ou os pobres, enquanto Dilma é uma política e uma economista desenvolvimentista dotada de forte capacidade administrativa. Conforme afirmou Luiz Werneck Vianna9 "mais do que gestora, Dilma investe-se do papel de primeira executiva em geral do capitalismo brasileiro, concebido como um projeto nacional a ser implementado de modo decisionista pelo Poder Executivo e sua sofisticada tecnocracia". Não sei até que ponto a presidenteé mais "decisionista" do que são os presidentes brasileiros no quadro do presidencialismo de coalizão vigente no Brasil, mas certamente pensa em liderar um projeto nacional com amplo apoio da sociedade.

Nessa direção, deu um passo importante quando sensibilizou as classes médias com uma postura ética forte. Sabemos que o capitalismo é uma forma intrinsecamente corrupta de organização da sociedade. O ganho pessoal sob todas as formas possíveis faz parte de sua lógica mais profunda. Por outro lado, a classe capitalista nunca se sente à vontade com a democracia. O financiamento privado de campanhas eleitorais foi sempre a estratégia capitalista para manter dependentes os políticos, e acusá-los de corrupção, sua estratégia para desmoralizá-los e, assim, limitar a autonomia da democracia. De repente, vimos um governo de esquerda, logo no começo de sua gestão, preocupar-se com a corrupção sem, porém, cair no moralismo conservador voltado para a desmoralização da política e dos políticos. A firmeza pela qual a presidente demitiu ministros foi surpreendente e agradou a classe média brasileira - uma classe que desde a transição democrática vem abandonando sua postura progressista e votando cada vez mais nos partidos conservadores.

Por outro lado, a presidente tem buscado reafirmar seu compromisso e o de seu partido político, o PT, com os trabalhadores e os pobres. É cedo ainda para avaliar o governo Dilma, mas há indicações de que estamos diante de uma estadista em construção. Primeiro, foi a firmeza que vem mostrando em baixar os juros enfrentando para isso muitos interesses, inclusive os de seus eleitores, pequenos poupadores; em seguida, foi o discurso na instalação da Comissão da Verdade, em que fez uma bela defesa dos direitos humanos e do seu caráter suprapartidário; finalmente, foi sua decisão histórica de, aplicando a Lei de Acesso à Informação, publicar os salários dos servidores do Executivo - um direito inconteste dos cidadãos, que até então vinha sendo negado. Todos, atos que mostram coragem e firmeza

Alguns poderão dizer que meu julgamento em relação à presidente é apressado. De fato, é cedo para dizermos que Dilma Rousseff preenche as condições muito raras que definem um estadista. Mas nos primeiros 26 meses de seu governo ela estava claramente "se construindo" 
como estadista; estava demonstrando a firmeza e a coragem que são necessárias. Mas não basta isso. Conforme disse classicamente Maquiavel, além da virtú, o príncipe necessita dafortuna.Virtú não significa apenas virtude, e sim competência em governar, discernimento ao tomar decisões, capacidade de fazer compromissos, e, finalmente, bom êxito em seu governo; fortuna é a sorte. Estadista é o governante que tem a visão do todo, olha para o futuro, e tem a coragem de buscá-lo, confrontando os interesses de muitos, inclusive dos seus seguidores. É quem conhece seu país, sabe quais são seus grandes problemas, e contribui de forma decisiva para resolvê-los. Os estadistas são geralmente identificados nas guerras em defesa de seu país, mas podem sê-lo em momentos decisivos de seu desenvolvimento econômico e social. O estadista brasileiro do século XX foi Getúlio Vargas, porque comandou a revolução nacional e industrial brasileira. A presidente Dilma Rousseff poderá ser uma nova estadista, agora em um contexto democrático, se lograr vencer os dois grandes males brasileiros: a alienação nacional de suas elites e a armadilha da alta taxa de juros e do câmbio sobreapreciado.

LUiz CARLOS BRESSER-PEREIRAé professor emérito da Fundação Getúlio Vargas. Contato: www. bresserpereira.org.br.

Recebido para publicação em 8 de fevereiro de 2013 . NOVOS ESTUDOS CEBRAP 95, março 2013 pp. 5-14 


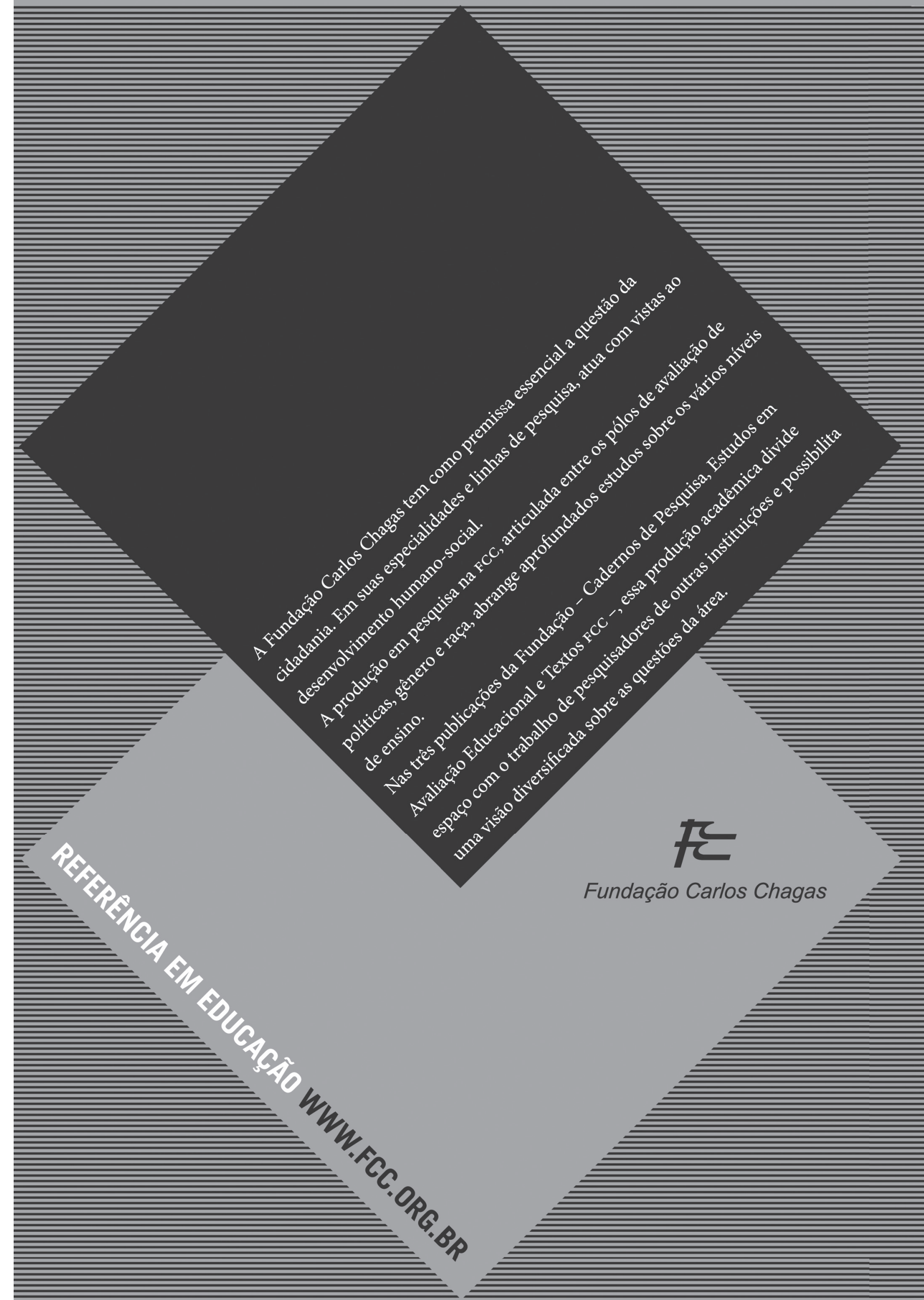

